\title{
Study on Thermal Properties and Mechanical Properties of Short-cut Polyimide-Fiber Reinforced Polyphenyl Sulfone Composites
}

\author{
Weizhou Yao ${ }^{1}$, Jianan $\mathrm{Yao}^{1}$, Qing $\mathrm{Jiao}^{2}$, Yunhai Wei ${ }^{1}$, Tianpeng $\mathrm{Yu}^{1}$, Youhai $\mathrm{Yu}^{1}$ and Hui $\mathrm{Li}^{1, \mathrm{a}}$ \\ ${ }^{1}$ School of Materials Science and Engineering, Donghua University, 201600 Shanghai, China \\ ${ }^{2}$ Beijing Institute of Remote Sensing Equipment, 100000, Beijing, China
}

\begin{abstract}
In order to increase the thermal stability and mechanical property of PPSU, two different polyimide (PI) short cut fibers reinforced polyphenyl sulfone (PPSU) composites were prepared by melt extrusion using a threescrew extruder. In addition, the effects of fiber lengths on thermal stability, heat resistance and mechanical properties of the composites was studied. The results indicate that the addition of polyimide chopped fiber can greatly improve the heat resistance of the composites. Comparing with PPSU, with the increasing of fiber content, the heat deformation temperature (HDT) of composites increased from $205{ }^{\circ} \mathrm{C}$ to $229^{\circ} \mathrm{C}$, but the addition of polyimide fiber has limited effect on the thermal stability of the composites. Meanwhile, the addition of polyimide chopped fiber can also improve the mechanical properties of the composites. Compared with PPSU, the tensile strength of composites can be increased by $102 \%$, and the bending strength can be raised by $117 \%$.
\end{abstract}

\section{Introduction}

With the continuous progress of the society, the requirements for material performance are becoming higher and higher. The excellent properties of composites and modified materials have greatly expanded their application fields. Polysulfone resin is a new type of thermoplastic engineering plastics that has emerged since the 1960s, including polysulfone, polyether sulfone, and polyphenyl sulfone[1-2]. As a typical representative of polysulfone resin, PPSU has excellent mechanical properties, heat resistance, flame retardancy, creep resistance, chemical stability and transparency. It has been widely applied in electronic, automotive, medical and health fields[3].

PI fibers[4], because of its excellent mechanical properties and resistance to radiation ability, excellent thermal stability and good dielectric properties[5-7], are widely used in electricity, microelectronics engineering and space[7-9]. As a kind of high performance organic fiber, PI fiber reinforced composites have attracted increasing attention because of their light weight, high strength and strong toughness in recent years[10]. Because polyimide has a rigid chain molecular structure, its fiber has the excellent mechanical properties, especially in tensile modulus[11]. According to the reports, Russia has developed a high strength polyimide fiber, its tensile strength can reach to $5.8 \mathrm{GPa}$, modulus up to $285 \mathrm{GPa}[12]$. Except to have the properties of high strength and high modulus, polyimide fiber also has excellent properties of high temperature resistance and radiation resistance. As an organic fiber, there are many

a Corresponding author: lihui@dhu.edu.cn kinds of composite materials made of organic fiber in the world.

Takayanagi[13] used modified Kevlar fibers to enhance LDPE. It was found that when the carboxymethyl volume fraction of the fiber surface was 2.2, the mechanical properties of LDPE increased significantly. Zhao[14] et al. reported that Kevlar fiber and nylon 6 fiber reinforced thermoplastic polypropylene can improve the mechanical properties and heat resistance of composites. $\mathrm{Fu}[15]$ investigated on fiber interfacial properties and fiber orientation enhancement effect properties of olefin copolymer composites of Kevlar fiber. Maity[16] and Vaisman[17] studied the UHMWPE fiber reinforced low density and high density polyethylene, and found that the enhancement effect is not obvious.

As far as we all know, it is rarely reported that polyimide fiber as reinforcing materials to prepare composites. In this study, we use two different types, different length of polyimide fiber to reinforce polyphenylene sulfone by extruding and blending. PI fiber reinforcing the PPSU composites can effectively improve the mechanical properties which can apply in harsh environment. Morever, we found that the PI/PPSU composites possessed the best comprehensive properties when the PI fibers content is $30 \%$.

\section{Materials and Method}

\subsection{Material}


PPSU powder was purchased from Shandong Haolan special plastic Co., Ltd (China). Short-chopped PI fiber ( $3 \mathrm{~mm}, 6 \mathrm{~mm}$ ) was purchased from Jiangsu SHINO new Mstar Technology Ltd (China). Another short-chopped PI fiber (6 mm) was purchased from Jiangsu AOSHEN new Mstar Technology Ltd (China).

\subsection{Preparation and Measurement}

PPSU powder and PI fiber were first pre-mixed in a highspeed mixer (HSR-800, Shandong Huanxin Co., Ltd) at $18 \mathrm{rpm}$ for $30 \mathrm{~min}$. The mixture was dried in an oven at $120{ }^{\circ} \mathrm{C}$ for $2 \mathrm{~h}$ before extrusion. The content of PI fiber added was varied at $10 \mathrm{wt} \%, 20 \mathrm{wt} \%$ and $30 \mathrm{wt} \%$ of the blends. The blends were prepared using a three-screw extruder (MEDI-22/40, Guangzhou Putong experimental analysis instrument Co., Ltd.) with a screw speed of 150 $\mathrm{rpm}$ at a temperature range of $340 \sim 350{ }^{\circ} \mathrm{C}$. The pellets were obtained by a granulator (Magelis, Guangzhou Putong experimental analysis instrument Co., Ltd.) and then shaped by an injection molding machine (TAYU400, Hangzhou TAYU Machinery Co., Ltd) to produce rectangular and dumbbell-shaped standard specimens. Injection molding conditions were as follows: Injection pressure $(90 \sim 140 \mathrm{MPa})$, Injection flow rate $(80 \sim 99 \%)$, Pressure holding pressure $(90 \sim 140 \mathrm{MPa})$, barrel temperature $\left(340 \sim 350{ }^{\circ} \mathrm{C}\right)$, injection molding temperature $\left(100 \sim 120^{\circ} \mathrm{C}\right)$, injection time (10 s) and Pressure holding time (10 s).

The weight loss was measured on a thermogravimetric analyzer TGA 2050 (TA instrument company, USA) under nitrogen and air at a flow rate of $100 \mathrm{~mL} / \mathrm{min}$ and a heating rate of $10{ }^{\circ} \mathrm{C} / \mathrm{min}$ from $50{ }^{\circ} \mathrm{C}$ to $800{ }^{\circ} \mathrm{C}$. The heat resistance tests were carried out on a Ceast 500 ALOXIDE high temperature thermal deflection temperature/Vicat apparatus with a heating rate of $2{ }^{\circ} \mathrm{C} / \mathrm{min}$ and a pressure of $1.82 \mathrm{MPa}$ in accordance with GB/T 1634-2004.

For GB/T 1040.2-2006, the stretch specimens were dumbbell-shaped with dimensions of $75.0 \times 12.5 \times 2.0$ $\mathrm{mm}^{3}$. For GB/T 9341-2008, the bending specimens had a size of $80 \times 10 \times 4 \mathrm{~mm}^{3}$. Tensile test was performed on a Shimadzu AG-1 universal testing machine at room temperature. Three-point bending test was performed on a Shimadzu AG-X $(20 \mathrm{kN})$ universal testing machine at room temperature. Spans for tensile and bending tests were $20 \mathrm{~mm}$ and $60 \mathrm{~mm}$, and the crosshead speeds were 5 and $2 \mathrm{~mm} / \mathrm{min}$, respectively.

Impact strength was tested on a charpy impact testing machine (HIT-2492, Chengde Jinjian Detection Equipment Co., Ltd) according to GB/T 9341-2000. The impact speed was $2.9 \mathrm{~m} / \mathrm{s}$. The data reported were average values of ten samples.

The morphology of the tensile section and the quenching morphology with liquid nitrogen are observed by a scanning electron microscope (SEM-450, FEI, Netherlands), operating at a $15 \mathrm{kV}$ accelerating voltage. The surfaces were all sprayed with gold before scanning.

The DMA Q800 dynamic mechanical analyzer (TA instrument company, USA) was used to measure the composite in air atmosphere. The three point bending mode is used to determine, the temperature range is 50$300{ }^{\circ} \mathrm{C}$, the amplitude is $10 \mu \mathrm{m}$ and the frequency is $1 \mathrm{~Hz}$.

\section{Results and Discussion}

\subsection{Thermal Stability}

TGA and HDT results of different kinds and contents of PI fiber reinforced PPSU composites are presented in Table 1. Both SHINO fiber and AOSHEN fiber, $\mathrm{T}_{\mathrm{d} 5}$ and $\mathrm{T}_{\mathrm{d} 10}$ of the composites were higher than the PPSU. However, with the difference of polyimide fiber content, $\mathrm{T}_{\mathrm{d} 5}, \mathrm{~T}_{\mathrm{d} 10}$ and HDT of the composites showed little difference, which indicates that the content of PI fiber has less effect on thermal stability. In addition, different types and different length of PI fiber showed the same heat deformation temperature of composites.

Table 1. Thermal stability of PI fiber reinforced PPSU composites.

\begin{tabular}{|c|c|c|c|}
\hline Samples & $\mathrm{T}_{\mathrm{d} 5}{ }^{1} /{ }^{\circ} \mathrm{C}$ & $\mathrm{T}_{\mathrm{d} 10}{ }^{1} /{ }^{\circ} \mathrm{C}$ & $\mathrm{HDT}^{2} /{ }^{\circ} \mathrm{C}$ \\
\hline PPSU & 560 & 572 & $205 \pm 2$ \\
\hline $\begin{array}{c}10 \% \text { SHINO- } \\
3 \mathrm{~mm}\end{array}$ & 565 & 576 & $221 \pm 1$ \\
\hline $\begin{array}{c}20 \% \text { SHINO- } \\
3 \mathrm{~mm}\end{array}$ & 563 & 577 & $220 \pm 1$ \\
\hline $\begin{array}{c}30 \% \text { SHINO- } \\
3 \mathrm{~mm}\end{array}$ & 564 & 577 & $221 \pm 1$ \\
\hline $\begin{array}{c}30 \% \text { SHINO- } \\
6 \mathrm{~mm}\end{array}$ & 564 & 576 & $229 \pm 1$ \\
\hline $\begin{array}{c}30 \% \text { AOSHE } \\
\text { N-6mm }\end{array}$ & 566 & 576 & $216 \pm 3$ \\
\hline
\end{tabular}

$5 \%$ weight loss $\left(\mathrm{T}_{\mathrm{d} 5}\right)$ and $10 \%\left(\mathrm{~T}_{\mathrm{d} 10}\right)$ weight loss temperatures measured by TGA under air.

${ }^{2}$ Heat deformation temperature.

Figure 1(a) (b) showed that the addition of PI fiber can improve the thermal deformation temperature of the composites, and the thermal deformation temperature is up to $23{ }^{\circ} \mathrm{C}$ higher than that of the neat PPSU. This is because PI fiber had a skeleton supporting effect, which hindered the effect of load on material under high temperature. The effect of SHINO fiber on the thermal deformation temperature of composites is greater than that of AOSHEN fiber, this is because the SHINO fiber has a rough surface compared with the AOSHEN fiber, and this lead a better bond properties with the resin matrix. At the same time, the thermal deformation temperature of the composites was also affected by different fiber length. With the same content, the thermal deformation temperature of $6 \mathrm{~mm}$ SHINO fiber reinforced composites was higher than $3 \mathrm{~mm}$, which should attribute to the longer length of the fiber, the better supporting effect for composites material, especially under the high temperature. 
(a)

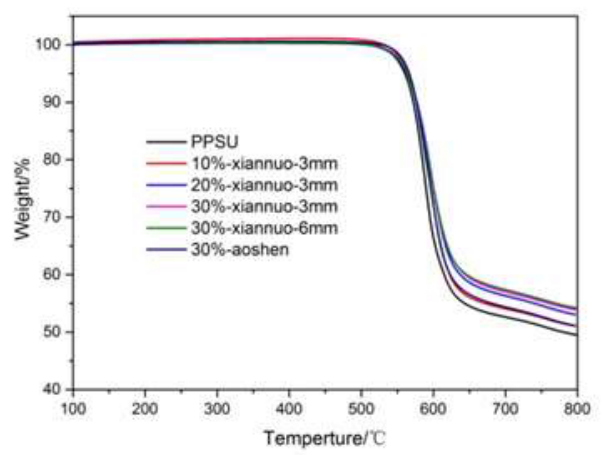

(b)

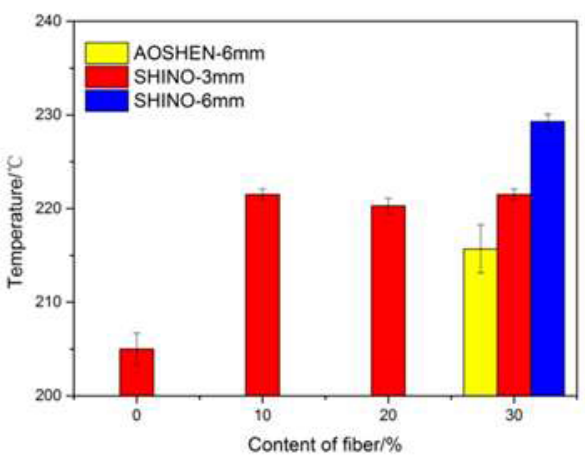

Figure 1. (a) TGA curves of PI fiber reinforced PPSU composites; (b) The bar graph of heat deflection temperature (HDT) of PI fiber reinforced PPSU composites.

\subsection{Dynamic Mechanical Analysis}

(a)

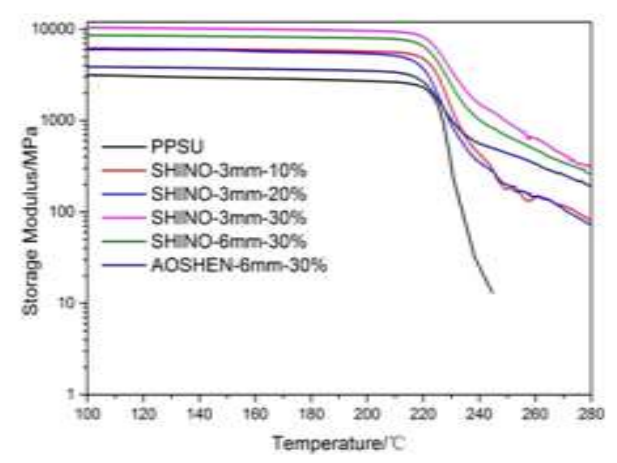

(b)

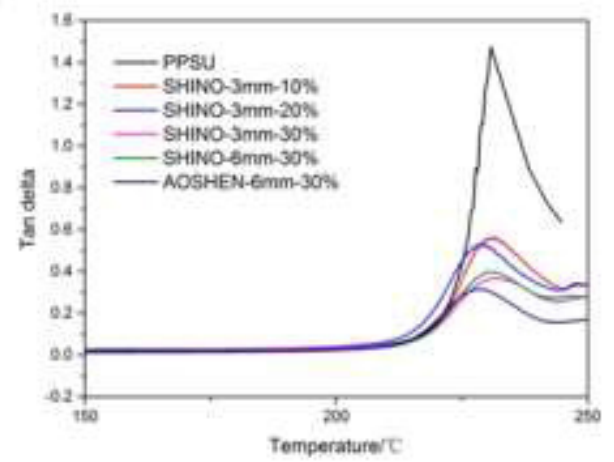

Figure 2. (a) The storage modulus curves of PI fiber reinforced PPSU composites; (b) Tan delta curves of PI fiber reinforced PPSU composites.
The storage modulus and tan delta of the different kinds and contents of the PI fiber reinforced PPSU composites are presented in Figure 2. The storage modulus of PI fiber reinforced composites is between $6.5 \mathrm{GPa} \sim 10.7 \mathrm{GPa}$. Compared with the neat PPSU, storage modulus of the PPSU composites increased greatly, of which 30\% SHINO-6mm fiber reinforced PPSU composites were approximately 3.2 times higher than that of the PPSU. In addition, with the increase of fiber content, the storage modulus of composite materials will also increase. Different kinds of fibers also influence on the storage modulus of the composites. With the same content, the storage modulus of SHINO fiber reinforced composites is higher than that of the AOSHEN fiber reinforced composites.

\subsection{Mechanical Properties}

The mechanical properties of the different kinds and contents of the PI fiber reinforced PPSU composites are listed in Table 2. The tensile strength of the composites increased with the increasing of PI fiber content. The tensile strength of the $30 \%$ SHINO fiber reinforced composites increased by about $106 \%$ compared with the neat PPSU. With the same content, the tensile strength of the $6 \mathrm{~mm}$ SHINO fiber reinforced PPSU composite is lower than that of the $3 \mathrm{~mm}$ SHINO fiber reinforced PPSU composite. The increase of fiber length will lead to fibers entanglement in the matrix resin, so that the tensile properties not be improved. Figure 3 (a) exhibited that the entanglement of $3 \mathrm{~mm}$ SHINO fiber reinforced PPSU composite is seldom seen, while that of $6 \mathrm{~mm}$ SHINO fiber reinforced PPSU composite is obvious. AOSHEN fiber can also improve the tensile strength of the composites. Compared with the matrix resin, the tensile strength of $30 \%$ AOSHEN fiber reinforced composites was increased by $81 \%$.

Table 2. Thermal stability of PI fiber reinforced PPSU composites.

\begin{tabular}{|c|c|c|c|c|c|}
\hline Samples & $\begin{array}{c}\text { Tensile } \\
\text { strength } \\
(\mathrm{MPa})\end{array}$ & $\begin{array}{c}\text { Tensile } \\
\text { modulus } \\
(\mathrm{GPa})\end{array}$ & $\begin{array}{c}\text { Flexural } \\
\text { strength } \\
(\mathrm{MPa})\end{array}$ & $\begin{array}{c}\text { Flexural } \\
\text { modulus } \\
(\mathrm{GPa})\end{array}$ & $\begin{array}{c}\text { Impact } \\
\text { strength } \\
\left(\mathrm{kJ} \cdot \mathrm{m}^{-2}\right)\end{array}$ \\
\hline PPSU & 69.5 & 1.0 & 79.6 & 2.2 & 32.2 \\
\hline $\begin{array}{c}10 \% \mathrm{SHI} \\
\mathrm{NO}-3 \mathrm{~mm}\end{array}$ & 109.1 & 1.5 & 118.9 & 4.2 & 10.9 \\
\hline $\begin{array}{c}20 \% \mathrm{SHI} \\
\mathrm{NO}-3 \mathrm{~mm}\end{array}$ & 126.8 & 1.1 & 144.7 & 6.1 & 11.2 \\
\hline $\begin{array}{c}30 \% \mathrm{SHI} \\
\mathrm{NO}-3 \mathrm{~mm}\end{array}$ & 140.6 & 0.6 & 166.0 & 7.7 & 13.5 \\
\hline $\begin{array}{c}30 \% \mathrm{SHI} \\
\text { NO-6mm }\end{array}$ & 123.7 & 0.7 & 172.5 & 7.2 & 15.7 \\
\hline $\begin{array}{c}30 \% \mathrm{AOS} \\
\mathrm{HEN}- \\
6 \mathrm{~mm}\end{array}$ & 126.3 & 1.2 & 94.6 & 2.8 & 21.3 \\
\hline
\end{tabular}

The flexural strength of the different kinds and contents of the PI fiber reinforced PPSU composites are presented in the Figure 3 (b). Obviously, the addition of polyimide fibers can improve the flexural strength of the PI fiber reinforced PPSU composites, and the flexural strength of the composites increases with the increase of 
fiber content. In addition, the flexural strength of the 30\% SHINO fiber reinforced composites increased by about $117 \%$ compared with the flexural strength of the matrix resin. With the same content, the flexural strength of $6 \mathrm{~mm} \mathrm{30 \%} \mathrm{SHINO} \mathrm{fiber} \mathrm{reinforced} \mathrm{PPSU} \mathrm{composites} \mathrm{is}$ higher than that of $3 \mathrm{~mm}$ SHINO fiber reinforced PPSU composites, and the flexural strength of $6 \mathrm{~mm}$ SHINO fiber reinforced PPSU composite is lower than $6 \mathrm{~mm}$ AOSHEN fiber reinforced PPSU composites.

Figure 3(c) shows the flexural modulus of composites, the addition of polyimide fibers can also improve the flexural modulus of the SHINO fiber reinforced PPSU composites. With the increasing of polyimide fiber content, the flexural modulus of the SHINO fiber reinforced composites increased gradually. However, the addition of fibers does not enhance the flexural modulus of the AOSHEN fiber reinforced PPSU composites. These might be attributed to the interfacial compatibility between the AOSHEN fiber and the matrix resin is not high, which lead to the flexural modulus of the fiber reinforced PPSU composites will no longer increase when reaching a certain content.

As shown in Figure 3(d), the impact strength of fiber reinforced composites through the decline after rising stage, which is attributed to the matrix of the composite was PPSU, its high toughness, high energy absorption per unit area, and joined the polyimide fibers, the toughness and brittleness increased, resulting in impact strength decreases. With the increasing of fiber content, fiber toughness play a role, cause the absorption composite unit area energy increases, the toughness is improved.

(a)

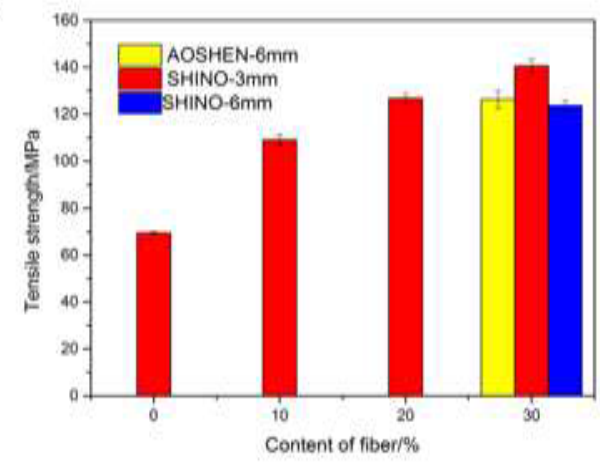

(b)

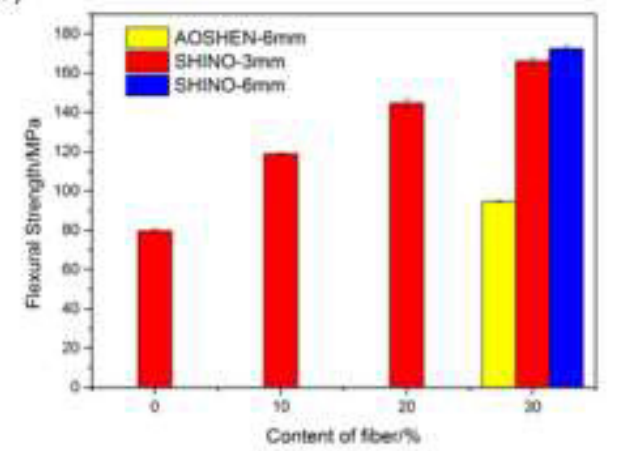

(c)

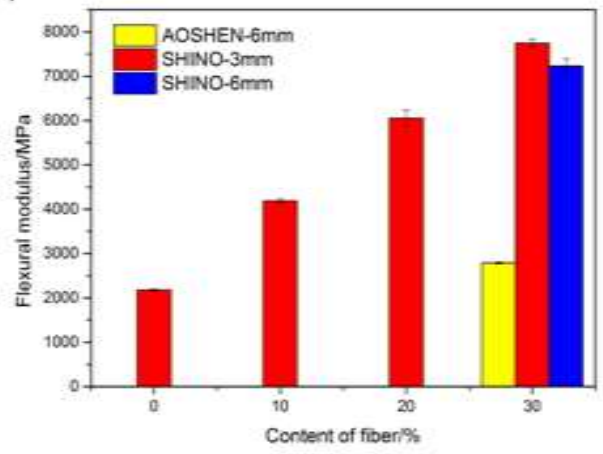

(d)

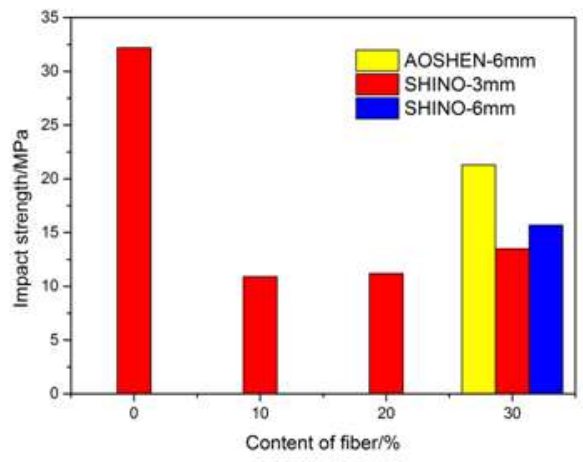

Figure 3. The bar graph of Mechanical properties of PI fiber reinforced PPSU composites. (a) Tensile strength; (b) Bending strength; (c) Bending modulus; (d) Impact strength.

\subsection{Scanning Electron Microscope}
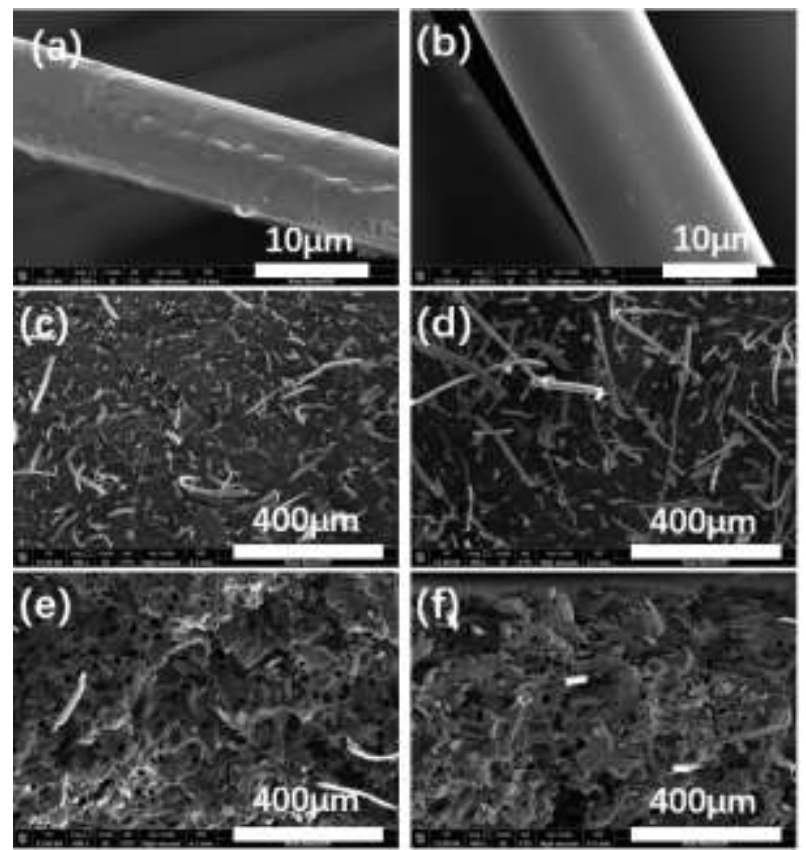

Figure 4. Scanning electron microscope photographs of (a) SHINO fiber; (b) AOSHEN fiber;(c)Tensile section of 3 $\mathrm{mm}$ SHINO fiber; (d) Tensisile section of $6 \mathrm{~mm}$ SHINO fiber composite; (e) Tensile section of $6 \mathrm{~mm}$ AOSHEN fiber composite. (f) The quenching section of $6 \mathrm{~mm}$ AOSHEN fiber composite. 
Figure 4 shows the scanning electron microscope photographs of fibers and composites. Two different kinds of fiber with different roughness, the surface of the AOSHEN fiber is more smoothly, but the surface of the SHINO fiber is relatively rough, which leads to a different bonding degree between the two fiber and resin. Figure 4(c), (d), (e), (f) shows that the two kinds of fiber reinforced composites with fewer holes pulled out when the fiber reinforced PPSU composite is stretched, while the holes of the AOSHEN fiber reinforced composite are more than that of the resin, that is because the bonding strength of the SHINO fiber and the resin is higher than the bonding strength of the AOSHEN fiber and the resin. In addition, from these four pictures, we can see that the $3 \mathrm{~mm}$ fiber is not curly and entangled in the resin. However, $6 \mathrm{~mm}$ fiber reinforced PPSU composites, regardless of the SHINO fiber or AOSHEN fiber, can clearly see the curly and entangled condition.

\section{Conclusions}

In this article, two kinds of polyimide fiber reinforced PPSU composites were prepared by a parallel three-screw extruder, and subsequently injection molding. The influence of different lengths of PI fiber, different kinds of PI fiber on composites properties were investigated, such as thermal stability and mechanical property. The $\mathrm{T}_{\mathrm{d} 5}$ of two kinds of fiber reinforced composites was in the range of $560{ }^{\circ} \mathrm{C} \sim 570{ }^{\circ} \mathrm{C}$ and $\mathrm{T}_{\mathrm{d} 10}$ was $570{ }^{\circ} \mathrm{C} \sim 580{ }^{\circ} \mathrm{C}$. The results indicated that polyimide fibers have limited effect on the thermal stability of the composites. However, the addition of two kinds of polyimide fibers can greatly improve the heat resistance of composites. The HDT of PPSU composites containing 30\% PI fiber was enhanced from $205^{\circ} \mathrm{C}$ to $229^{\circ} \mathrm{C}$ comparing with neat PPSU. PI fiber reinforced PPSU composites showed higher tensile strength and flexural strength than neat PPSU, the same as to flexural modulus. Moreover, owing to the SHINO fiber is more rough than AOSHEN fiber, so SHINO fiber with PPSU showed better compatibility than AOSHEN fiber with PPSU, then the SHINO fiber reinforced PPSU composites exhibited better thermal properties and mechanical properties than AOSHEN fiber reinforced PPSU composites.

\section{References}

1. Chen,X.; Zhao, J. Q.; Yuan,Y.C.; et al. Synthesis, properties and applications of sulfone polymers. Guangdong Chemistry 2013, 18(40), 66-67.

2. Bian, J.; He, X.F.; Lin, H.L.; Wang, G.; et al. Polyphenylene sulfone/graphene nanocomposites preparation and properties. Journal of Chinese Universities 2015, 29(5), 1230-1237.

3. Wu, J G.; Li, L J.; Guo, H T. Research advance on polysulfone and its composites. China plastics Industry. 2009, 3(7), 9-12.

4. Luong, N O.; Hippi, U.; Korhonen J T.; et al. Enhanced mechanical and electrical properties of polymide film by graphene sheets via in Situ polymerization. Polymer 2011, 52(23); 5237-5242.
5. Niu, H.; Huang, M, Qi, S.; et al. High-performance copolymide fiber contaning quinazolione moiety.: Preparation, Structure and properties[J]. Polymer 2013, 54(6), 1700-1708.

6. Zhang, M Y.; Niu, H Q.; Qi, S L.; et al. Structure evolutions involved in the carbonization of polymide fibers with different chemical constitution. Materials Today Communicaions 2014, 1(1-2), 1-8.

7. Chang,J.; Ge, Q.; Zhang, M.; et al. Effect of preimidization on the structures and properties of polymide fibers. RSC Adv 2015, 5(85), 69555-69566.

8. Yin, C.; Dong, J.; Tan, W.; et al. Strain-induced crystallization of polymide moiety. Polymer 2015, 75, 178-186.

9. Chang, J.; Liu, M.; et al. Structures and properties of polymide fibers containing fluorine groups. RSC Adv 2015, 5(87), 71425-71432.

10. Zhang, Q H.; Chen, D J.; Ding, M X. Polymide fiber. Chinese Polymer Bulletin. 2001, 5, 66-72.

11. Liu, X Y; Gu, Y. High performance polymide fibers. New chemical materials. 2005, 5(33), 14-17.

12. Zhang, Q H; Zhang, C H, Chen, D J; Ding, M X. High tech fiber and its application. 2002, 27(5).

13. Takayanagi, M.; Kajiyama, T.; Katayose T. Surfacemodified kevlar fiber-reinforced polyethylene and ionomer. Journal of Applied Polymer Science 1982, 27(10), 3903-3917.

14. Zhao, S.; Cheng, L.; Guo, Y.; et al. PA6 and Kevlar fiber reinforced isotactic polypropylene: Structure, mechanical properties and crystallization and melting behavior. Materials \&Design 2012, 35,749-753.

15. Fu, S.; Yu, B.; Duan, L.; et al. Combined effect of interfacial strength and fiber orientation on mechanical performance of short Kevlar fiber reinforced olefin block copolymer. Composites Science and Technology 2015, 108, 23-31.

16. Maity, J.; Jacob, C.; Das, C K.; et al. Direct fluorination of UHMWPE fiber and preparation of fluorinated and non-fluorinated fiber composites with LDOE matrix. Polymer Testing 2008, 27(5), 581-590.

17. Vaisman, L.; Gonzalez, M F.; Marom, G. Transcrystallinity in brominated UHMWPE fiber reinforced HDPE comosites: morphology and dielectric properties. Polymer 2003, 44(4), 12291235 . 